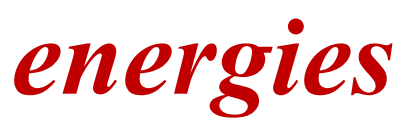

ISSN 1996-1073

www.mdpi.com/journal/energies

Article

\title{
Decentralized Energy from Waste Systems
}

Blanca Antizar-Ladislao ${ }^{1, *}$ and Juan L. Turrion-Gomez ${ }^{2}$

1 Institute for Infrastructure and Environment, School of Engineering, University of Edinburgh, UK

2 Rothamsted Research, Centre for Bioenergy and Climate Change, Department of Plant \& Invertebrate Ecology, Harpenden, Hertfordshire AL5 2JQ, UK;

E-Mail: juan.turrion-gomez@bbsrc.ac.uk

* Author to whom correspondence should be addressed; E-Mail: B.Antizar-Ladislao@ed.ac.uk; Tel.: +44(0)131-650-5712; Fax: +44(0)131-650-6781.

Received: 4 December 2009 / Accepted: 25 January 2010 / Published: 28 January 2010

\begin{abstract}
In the last five years or so, biofuels have been given notable consideration worldwide as an alternative to fossil fuels, due to their potential to reduce greenhouse gas emissions by partial replacement of oil as a transport fuel. The production of biofuels using a sustainable approach, should consider local production of biofuels, obtained from local feedstocks and adapted to the socio-economical and environmental characteristics of the particular region where they are developed. Thus, decentralized energy from waste systems will exploit local biomass to optimize their production and consumption. Waste streams such as agricultural and wood residues, municipal solid waste, vegetable oils, and algae residues can all be integrated in energy from waste systems. An integral optimization of decentralized energy from waste systems should not be based on the optimization of each single process, but the overall optimization of the whole process. This is by obtaining optimal energy and environmental benefits, as well as collateral beneficial co-products such as soil fertilizers which will result in a higher food crop production and carbon dioxide fixation which will abate climate change.
\end{abstract}

Keywords: biofuels; carbon capture; fertilizer; integration; waste 


\section{Introduction}

Decentralized energy systems, which could include renewable sources and combined heat and power (CHP) stations are of particular interest in low carbon economies. Additionally, the use of biofuels for transport is becoming of increasing importance for a number of reasons, such as climate change, depleting fossil fuel reserves, and reducing reliance on imports [1,2]. Thus, the production of biofuels in Europe and imports from third countries has increased, and also concerns regarding additional environmental pressures inside and outside the EU. These concerns are mainly due to suboptimal use of biomass resources, finite nature of resources, poor energy efficiency, consequences of the intensification of biofuel production on arable land (increasing pressures on soil, water and biodiversity resources), import of biofuels and difficulties to achieve and to monitor sustainable production of biomass outside Europe [3].

Biofuels processed from renewable biomass, are suggested as a direct substitute for fossil fuels in transport. A recent study has revealed that bioethanol from biodegradable municipal solid waste offer a considerable potential for reducing green house gas emissions, compared to the current waste management situation in England [4]. Thus, current research and development drivers are the identification of potential renewable energy sources or biomass feedstock and their processing in order to produce alternatives to fossil fuels in transport, such as bioethanol, biodiesel, biomethanol and hydrogen $[5,6]$. Biofuels must be derived from biomass feedstock produced with much lower life-cycle greenhouse-gas emissions than traditional fossil fuels and with little or no competition with food production [7]. Currently, renewable energy sources represent about $14 \%$ of primary-energy consumption in the world, with biomass being the major contributor (i.e., about 10\%). Bioethanol is, by far, the most widely used biofuel for transport [5,8], and Brazil stands as the largest sugarcane bioethanol world's leading producer, supplying about half of the global market [9]. In fact, in 2005 Brazil produced 282,000 barrels of bioethanol a day, up from 192,000 barrels in 2001 [10].

The aim of this paper is to investigate the potential of decentralized energy from waste systems to produce biofuels.

\section{Energy from Waste}

\subsection{Energy from agricultural and wood residues}

The use of agricultural and wood residues may result in a lower overall cost in the biofuel process as compared to the cost of producing a tone of specially cultivated energy crops, where inputs must be invested to cultivate, fertilize and harvest them. However some biomass crops as short rotation coppice and perennial grasses have a great potential in sustainable biofuel production [11]. Agricultural residues such as bagasse and residues from the production of cereals, including maize, wheat, barley, rice and rye, are among the feedstocks that can be used to generate bioethanol. However, only about $15 \%$ of total residue production would be available for energy generation after accounting for needs related to soil conservation, livestock feed and factors such as seasonal variation [12]. Agricultural residues may become more important biofuel feedstock as bioenergy production increases, and their availability could increase through improved management practices. 
The wood industry produces large amounts of sawdust, wood chips and other wood residues that can be obtained from the forest. In 2005, 3.5 billion $\mathrm{m}^{3}$ of wood of 434 billion $\mathrm{m}^{3}$ of growing stock were removed from the forest, of which $60 \%$ was industrial round-wood and the rest fuel wood [13]. Plantations already provide $25 \%$ of the world's wood fiber supply; in New Zeeland, Pinus radiate plantations are on average 20-fold more productive than natural forest, whereas plantations of Eucalyptus hybrids in Brazil are 40-fold more productive [14]. However, destruction of natural forest can produce a negative or neutral carbon balance between the carbon stored in the forest and the carbon emissions reduced by the biofuel production [15]. Trees provide potentially higher calorific values for biofuel production than agricultural crops. In fact trees can achieve a lignocellulosic energy conversion factor of 16 (compared with 1-1.5 for corn and 8-10 for sugarcane), and can be grown in marginal agricultural land, reducing competition for space with food crops [16]. It is currently suggested that irrigated Saharan- and Australian-desert forests could sequester amounts of atmospheric $\mathrm{CO}_{2}$ at least equal to that from burning fossil fuels [17]. The development of high-output plantations to meet the increased demand for wood sustainably, and the natural forests for meeting carbon mitigation objectives while continuing to provide important ecosystem services such as clean water, or biodiversity, as well as delivering traditional forest products and services, have to be balanced $[13,18]$. Today, only a small proportion of liquid biofuels are forest-based, but the development of an economically viable process for producing cellulosic liquid biofuels could lead to the widespread use of forest biomass in the transport sector. In Scotland, Invicta Capital is seeking to raise a $£ 300 \mathrm{M}$ fund dedicated to the construction and operation of nine biomass combined heat and power plants, with a total generating capacity of up to $90 \mathrm{MW}$ of electricity, enough to supply 140,000 homes, and powered with wood been supplied from local sustainable and managed sources [19].

\subsection{Energy from municipal solid waste}

Municipal solid waste (MSW) represents an important source of biomass towards the production of biofuels [20,21]. Unprocessed MSW in Europe consists predominantly of paper/card, kitchen waste, garden waste, textiles, fines and miscellaneous (combustibles and others). Additionally, around 80\% MSW may be biodegradable to a given extent, averaging $65 \%$ biodegradability [20]. The biodegradable fraction present in MSW may be considered an alternative sustainable source of biofuel (i.e., bioethanol, biogas) [22]. This waste management strategy also encourages the reduction of greenhouse gas emission by diverting waste from landfill sites. Moreover, conversion of MSW will further optimize land use by decreasing material flows to landfills, and little or no resource investment except for MSW collection and separation will be required. Hence, potential drivers for advanced treatment sites of waste to energy are that they operate on a smaller scale and therefore have a smaller land requirement and overall carbon footprint. They are potentially suitable for industry to treat waste on their site, use the energy for their process and sell any excess to the grid. They may also be easier to gain planning permission for, as they are likely to be in existing industrial areas and require fewer vehicle movements, cutting down on concern over traffic and amenity impact. For example, bioethanol is produced from potato peelings from chip plants which have been identified as a potential fuel source in Northern Ireland [23]. The UK has been allocated a target to increase the proportion of its energy use provided from renewables to $15 \%$ by 2020 , and it is suggested that biomass could supply about a 
third of the required energy source. It has been recently approved the construction of an energy park in Peterborough with a generating capacity of $80 \mathrm{MW}$ of electricity, that will process mixed waste to produce sufficient energy to power 60,000 houses, save 600,000 tones of harmful $\mathrm{CO}_{2}$ per year, and reduced UK's carbon footprint, by diverting waste from landfills [19].

\subsection{Energy from vegetable oils}

Vegetable oils, extracted from oil seeds, crops, nuts, fruits and leaves, can be used as fuels for diesel engines (e.g. biodiesel or straight vegetable oil), but they are relatively expensive if grown as dedicated energy crops. A group of oil seeds bearing shrubs, such as Jatropha, castor bean, Pogamia Pinnata and Calophyllum inophyllum, have been used as first generation biofuels [24]. Jatropha may be the most highly promoted oilseed crop [25], although there is very little information available about this perennial shrub and its oil-bearing seed plant [24]. Jatropha may grow in extremely marginal (e.g., arid) sites, but high yield will be only obtained on fertile sites or with inputs of water and fertilizers, which makes its production less sustainable. Castor bean was initially promoted over half a century ago for specialty lubrication uses and for plastics, and now it is being reintroduced as a biodiesel crop, especially in Brazil [24]. Various other perennial shrubs bearing seeds with high oil content, such as Pogamia Pinnata and Calophyllum inophyllum, are being promoted, especially in India [24,26]. In Europe and Canada, rapeseed oil methyl ester (RME), produced from oilseed rape is the main substitute fuel, while soybean oil is used in the USA. Different oil seeds bearing shrubs will result in higher yields than others, for example Calophyllum inophyllum yields about twice as much oil per hectare as Jatropha [26]. Although the aforementioned oil seeds may add to second generation biofuels, there are many issues that need to be considered before full scale industry can be developed. So far most of the above mentioned crops are grown using manual labor, and they have not been domesticated to a point of human safety (i.e., they have poisonous substances) [26]. Future research should be oriented towards domestication of oil seeds bearing shrubs, in order to increase the harvest index (seed yield divided by biomass), facilitate mechanical harvesting, and suppress the formation of toxic substances, and thus used as second generation biomass feedstock [24]. Residues of biodiesel production and plants could be integrated in further biofuel production as biogas or bioethanol.

British companies BP and D1 Oils have formed a joint venture called D1-BP Fuel Crops to accelerate the planting of Jatropha curcas, as a raw material source for biodiesel. The companies claim that the oilseed is a desirable biodiesel feedstock because it may not compete with food crops for good agricultural land or adversely impact the rainforest [27]. Waste oil made up of old cooking oil, expired oil from grain depots and waste oil from animal fats can also be use for biodiesel. Argent Energy's biodiesel plant at Newarthill, Motherwell, Scotland is one of the first in the UK to use waste cooking oil, produced by the fast food and catering industry, as feedstock for biodiesel [23].

\subsection{Energy from algae residues}

Biodiesel from algae seems to have the potential as the alternative renewable biofuel, replacing fossil-based fuels. Bioethanol can also be produced from algae by converting the starch and the cellulose. 
Algae grow naturally all over the world, either in freshwater or marine water, avoiding, if a sustainable design is used, the use of agricultural land. Under optimal conditions, it can be grown in massive amounts, almost limitless. Producing renewable biofuels from algae will have no conflict with food supply and also contribute to reducing greenhouse gas emissions. Algae are photosynthetic micro-organisms that convert sunlight, water, mineral nutrients and carbon dioxide into algal biomass. For this reason, algae biodiesel and biomass manufacturers are growing algae close to energy manufacturing plants that produce lots of carbon dioxide because algae increase its production with higher concentrations of carbon dioxide and the energy plant can reduce its carbon emissions. Some algae are rich in oil (lipid oil), up to $80 \%$ of the dry weight of the algal biomass [28]. Additionally, algae biofuel production can be coupled with flue gas $\mathrm{CO}_{2}$ mitigation, wastewater treatment and the production of high-value chemical co-products [29].

A conceptual process for producing microalgal oils for making biodiesel is suggested by Chisti [28]. It consists of a microalgal biomass production step that requires light, carbon dioxide, water and inorganic nutrients. In the biomass-recovery stage, the cells suspended in the broth are separated from the water and residual nutrients, which are then recycled to the biomass-production stage. The recovered biomass is used for extracting the algal oil that is further converted to biodiesel in a separate process. Some of the spent biomass can be used as animal feed and for recovering other possible high value products that might be present in the biomass. Most of the biomass undergoes anaerobic digestion, which produces biogas to generate electricity. Effluents from the anaerobic digester are used as a nutrient-rich fertilizer and as irrigation water. Most of the power generated from the biogas is consumed within the biomass-production process and any excess energy is sold to grid. Additionally, $\mathrm{CO}_{2}$ emissions from the power generation stage are fed into the biomass production.

But it is also suggested that the spent biomass could be diverted to a fermentation process to produce bioethanol. In fact, a team of Danish researchers at the National Institute of Environmental Research (NERI-DMU) investigate the production of bioethanol produced by green algae (Ulva lactuta). Early results indicated that this green algae produces 700 times more biomass per hectare than a traditional wheat field [30]. The Ulva lactuta and other similar species are very widespread in most regions of the world, particularly in eurotrophic zones where their abundance threatens local ecosystems: an environmental problem that the harvesting of algae and their transformation into biofuel could in fact, resolve.

One interesting example of bioethanol production from algae in Japan, the "Ocean Sunrise Project", uses Sargassum seaweed as a biomass feedstock. It utilizes 4.47 million $\mathrm{Km}^{2}$ of unused areas of the exclusive economic zone and maritime belts of Japan. 


\section{Decentralized Energy from Waste Systems}

The first large-scale schemes for biofuel production began in the early 1970s, however it is only in the last five years or so that biofuels have been given notable consideration worldwide as an alternative to fossil fuels [23]. Their greatest appeal lies in their potential to reduce greenhouse gas emissions by partial replacement of oil as a transport fuel. In a global market, energy and products are transported with a consequent waste of fossil fuels and $\mathrm{CO}_{2}$ production. If the biomass is produced thousands of kilometers far from where it is consumed, it will have a consequent $\mathrm{CO}_{2}$ release to the atmosphere, while the use of biomass is implemented to reduce $\mathrm{CO}_{2}$ release [31].

It is unarguable that current approaches of biofuel production results in considerable social benefits (e.g. generation of jobs), but also in some environmental and social backgrounds it can result in detrimental consequences, such as soil erosion, river basins contamination, air pollution, human respiratory diseases and extremely poor working conditions [10,32,33]. Environmental damage caused by current approaches urges us to recover the lost landscape efficiency [34]. More sustainable approaches should consider local production of biofuels, obtained from local feedstock and adapted to the socio-economical and environmental characteristics of the particular region where they are developed. In past organic agro-systems, livestock was fed and used as the main non-human source of power mainly dedicated to tillage and transport. Livestock manure was the main source of fertilizer for food crop production. Overall, this approach was based on an integral optimization of energy and material flows or land use efficiency [35]. Currently, an increase in biofuel production requires an increase in biomass production and perhaps its economic value, which may result in more profitable agro-systems, and potentially in the development of rural areas. Additionally, if biomass conversion industries are created in rural areas, where the biomass feedstock is, this will reduce the carbon footprint due to transport. Similarly, waste to energy could be a great source of biofuels particularly in or near urban centers where large quantities of biodegradable fractions of MSW are produced [20].

The production of biofuels should be economically beneficial, generate none or minimal $\mathrm{CO}_{2}$ or green-house gas emissions, contribute to rural development and to the production of energy at a local level as well as local distribution around villages, towns, cities and countryside. Thus, decentralized production of energy from waste could be based on the use of currently available or improved processes and technologies to produce energy even at a small scale at the site of origin of the waste. Additionally, it has been reported that the utilization of agricultural residues can increase the benefits per hectare of biomass cultivation significantly, by about 190 GJ per hectare per year and $15 \mathrm{Mg} \mathrm{CO}_{2}$ equivalent per hectare per year, thus increasing the landscape efficiency [36].

Issues that need to be addressed in the local context include mainly resource availability and competing uses, and economic access, reliability and accessibility [37]. Location of demand and supply and purchasing power versus cost are key issues. In poor rural areas a key concern is the competition of biomass energy systems with present use of biomass resources in applications such as animal feed and bedding, fertilizer and construction materials. These may be a higher priority to rural populations, as alternatives may not exist. Thus a very detailed and participatory resource assessment must be done before initiating action on bioenergy systems using existing resources. Additionally, economic access by poor rural societies to different bioenergy options is a key matter. The level of 
trade in fuel wood is on the increase. In remote areas or on islands, where fossil fuels are usually expensive due to transport costs, bioenergy systems may prove to be the most economical option.

Bioenergy options such as small and medium scale biogas or gasifiers and power generators operating with locally available biomass sources such as vegetable oils, biogas from manure, and agricultural and forestry by-products can become in some areas the most economical and reliable providers of energy services. Reliability, local maintenance and monitoring capacity, and accessibility of the technologies needed to make use of these resources are in many cases the key barriers.

A well established process at waste management facilities consists of composting the organic fractions of MSW to produce compost could be used to apply the concept of decentralized energy from waste systems. Using the same infrastructure, additional processes could be implemented to the bioconversion of organic fractions of MSW to biofuel. By-products may include a solid waste and a liquid waste which could be used in soil conditioning or further composted to obtain high quality compost. The biofuel generated during this process can be used for running the integrated process, including the use of biofuel in transport of waste from households to the waste management facilities. Overall this process will help to reduce the emission of greenhouse gases, offering a new solution for dealing with waste by providing a solution to reduce the amount of waste. In summary, in order to successfully apply decentralized systems one should contemplate the feasibility of the use of a wide range of biomass feedstock for the sustainable production of energy. Considering waste as biomass feedstock, there is a potential of increasing feedstock sources and thus production of energy. Nevertheless, there is a present need to improve and optimize current available conversion technologies of waste to energy, towards a lower process cost. It will be only then when the implementation of decentralized energy from waste systems will allow the partial substitution of fossil fuels by second generation biofuels.

\section{Integral Optimization of Decentralized Energy from Waste Systems}

The focus of energy from waste systems is not based on the optimization of each single process, but the overall optimization of the whole process, which is here defined as integral optimization. This is by obtaining optimal energy and environmental benefits, as well as collateral beneficial co-products such as soil fertilizers which will result in a higher food crop production yield and $\mathrm{CO}_{2}$ fixation which will abate climate change. This integral optimization is in agreement with the concept of biorefineries, defined as "the sustainable processing of biomass into a spectrum of marketable products" [38].

\subsection{Combined production of bioethanol, biogas and compost from waste}

Decentralized energy from waste systems should be flexible and robust, so they can process a variety of biomass feedstock to produce a variety of biofuels and co-products. As an example, Figure 1 presents the concept of a flexible energy from waste system, with the potential of taking waste biomass feedstock to produce bioethanol, biogas and compost. This concept is presented with a mass balance, which indicates the amount of biofuels and co-products based on 1 tonne of biomass feedstock and conversion factors from the bibliography. 
Figure 1. Combined production of bio-ethanol, bio-gas and fertilizer.

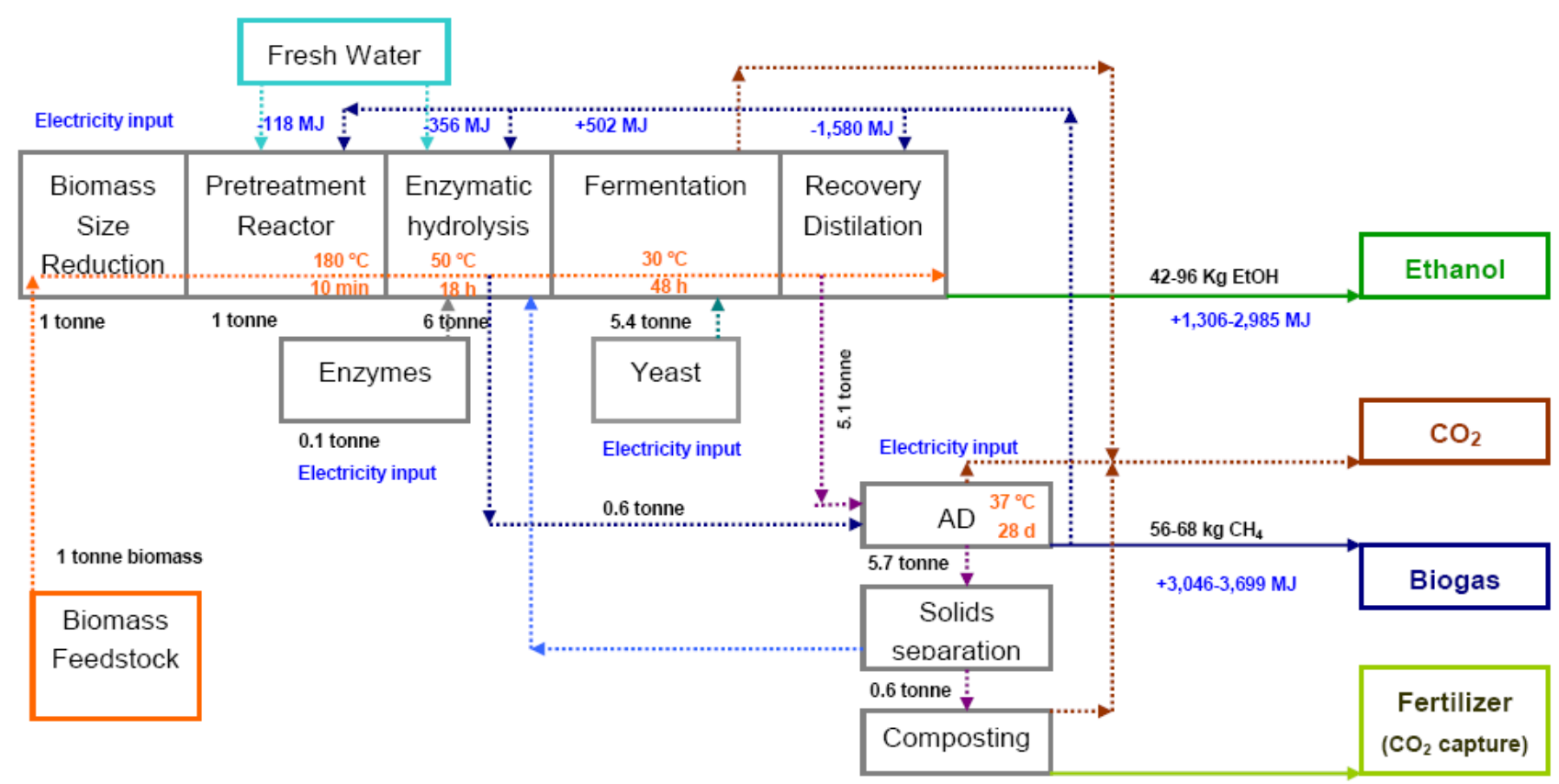

The biomass flows through a number of processes, to obtain the final products. These are: biomass size reduction, pre-treatment, enzymatic hydrolysis and fermentation. From the fermentation unit, the liquid phase goes to recovery/distillation, and both, the solid phase and rejects from the distillation unit goes to anaerobic distillation along with a solid fraction proceeding from the enzymatic hydrolysis unit. From the distillation unit, the main product is bioethanol. From the anaerobic unit, the main product is biogas $\left(\mathrm{CH}_{4}+\mathrm{CO}_{2}\right)$ which could be directly use for heating purposes in the energy from waste system or local heating systems. Upgrading this biogas is not recommended for decentralized systems for two reasons: firstly, the main product with highest added value is the bioethanol, and secondly, upgrading is a high cost and complicated process, which also requires a distribution network in place. A secondary product from the anaerobic unit is a solid fraction that goes to a composting unit to produce compost, which is an organic fertilizer that as above indicated, could be directly applied to the land.

Thus, assuming that $50 \%$ of 1 tonne of biomass waste is cellulose and hemicelullose, bioethanol (42-96 kg), methane (56-68 kg) and compost (300 kg) could be produced using a system similar to that presented in Figure 1 [39-41], with a production of energy of 1,306-2,985 MJ and 3,046-3,699 MJ from bioethanol and biogas production based on the mass balance, respectively.

In the case of Scotland, more than $5 \mathrm{M}$ of people live on a surface of $7.8 \mathrm{M} \mathrm{Ha}$ [http://www.scotland.org/about/fact-file/physical/index.html]. It is estimated that the total amount of waste biomass in Scotland can be about 4M tonne per year from the following sources: (i) $1.5 \mathrm{M}$ tonne per year from the biodegradable fraction of municipal solid waste; (ii) $1 \mathrm{M}$ tonne per year from garden waste; (iii) $0.4 \mathrm{M}$ tonne per year from spent grain; (iv) $1 \mathrm{M}$ tonne per year from excess of straw, not used in animal feed; (v) $0.1 \mathrm{M}$ tonne per year from forest residues [40,42]. The potential for biofuel production from waste biomass in Scotland is estimated to be in the range of 165,270 to 377,760 tonne of bioethanol per year (equivalent to 209 to $478 \mathrm{M}$ liters of bioethanol per year) and 220,360 to 267,580 tonne of methane per year. These calculations do not include values on energy 
crops, although it is recognized that Scotland has a huge potential for energy crops growth and subsequent production of biofuels.

Obviously, these rates change with biomass composition and process optimization. Bioethanol has a high commercial added value as a transport fuel, and thus the production of bioethanol will be favored. The production of compost offers a number of environmental advantages such as an increase in the soil fertility and health, which prevents the use of fertilizers (implying avoidance of greenhouse gases related to their production) and pesticides (avoiding emissions associated with their production). Compost also improves the soil structure (also tillage and workability implying less consumption of fuels), water capacity, and fixes carbon in the soil, as it accumulates humic substances which are persistent in the soil during decades. Nevertheless, the application of compost to soils requires an adequate soil management, such as using no aggressive tilling practices (which may lead to anaerobic conditions in the top-soil layer).

\subsection{Biochemical vs. thermochemical bioethanol from waste systems}

Biochemical (i.e., enzymatic hydrolysis, fermentation) and thermochemical (i.e., gasification, pyrolysis) technologies are competing to produce biethanol from waste. In fact, the National Renewable Energy Laboratory (NREL) is currently comparing and analyzing biochemical, gasification, and pyrolysis platforms to determine the most effective process to convert corn stover to biofuels [43]. The focus of biochemical processes is converting biomass to sugar or other fermentation feedstock, fermenting these biomass intermediates using biocatalysts, and processing the fermentation product to yield fuel-grade bioethanol and other biofuels. Currently, particular attention is given to pretreatment and enzymatic hydrolysis to decrease the costs and increase sugar yields by making the cellulosic and hemicellulosic more easily digestible by enzymes [20]. Main products of biochemical waste to energy technologies, if one follows the processes presented in Figure 1, are bioethanol, biogas and compost.

The focus of thermochemical processes is on gasification and pyrolysis technologies. Gasification, consists of heating biomass with about one third of the oxygen necessary for complete combustion, and produces a mixture of carbon monoxide and hydrogen, known as syngas. Pyrolysis, consists of heating biomass in the absence of oxygen, and produces a liquid, known as pyrolysis oil, and a solid known as biochar. Both syngas and pyrolysis oil can be used to make fuels that are cleaner and more efficient than waste. Currently, particular attention is given to the optimization of syngas production to reduce the cost of syngas cleanup, conditioning and conversion to other biofuels (e.g., bioethanol), and to the development of a cost-effective method bio-oil deoxygenation creating a bio-oil that can be upgraded to clean biofuel.

Future attention will be thus focused on the comparison between syngas-bio-oil-biochar technology and bioethanol-biogas-compost technology. General comparisons are quite difficult, as for example, the calorific value of the syngas will depend upon the composition of the input waste to the gasifier. Additionally, even if syngas has an enormous potential as a direct fuel, it can also be transformed to bioethanol or purified to hydrogen [3]. While biochar has the potential to store carbon and could be one of the solutions to climate change [44], it is still to be investigated whether biochar will be more beneficial to improve the quality of the soil and to store carbon than compost. 
Another important aspect to consider when comparing both technology systems is water. The production of bioethanol-biogas-compost requires approximately $80 \%$ of water for the optimum activity of biocatalysts, and thus wet biomass feedstock will be more suitable for this technology. On the other hand, syngas-bio-oil-biochar technologies require dry feedstocks, or in case of wet biomass feedstocks, these will need to be dried out prior to the thermochemical processes. Thus, dry biomass feedstocks will be more suitable for syngas-bio-oil-biochar technologies. In conclusion, the main factor that will determinate the efficiency of each technology will be the water content of the biomass feedstock.

\section{Conclusions}

Currently, decentralized energy from waste systems are receiving considerable attention. Organic fractions of waste that have traditionally been buried in landfills, can now be diverted and used as biomass feedstock for novel and/or adapted biochemical or thermochemical conversion process. Integrated and optimized bioenergy systems have the potential of contributing to the global greenhouse-gas reductions and the local environmental and societal benefits. Whether they can be implemented on a commercial scale, is uncertain.

\section{Acknowledgements}

Financial support provided by the University of Edinburgh through the Innovation and Knowledge Transfer Award is greatly appreciated. Comments of two anonymous reviewers are greatly appreciated.

\section{References}

1. European Union. Directive 2003/30/EC Of The European Parliament and of the Council of 8 May 2003 on the promotion of the use of biofuels or other renewable fuels for transport. Off. J. Eur. Union 2003, L123, 42-46.

2. Wingren, A.; Galbe, M.; Zacchi, G. Techno-economic evaluation of producing ethanol from softwood: Comparison of SSF and SHF and identification of bottlenecks. Biotechnol. Progr. 2003, 19, 1109-1117.

3. Antizar-Ladislao, B.; Turrión-Gómez, J.L. Second generation biofuels and local bio-energy systems. Biofuels, Bioprod. Biorefin. 2008, 2, 455-469.

4. Stichnothe, H.; Azapagic, A. Bioethanol from waste: Life cycle estimation of the greenhouse gas saving potential. Resour. Conserv. Recycl. 2009, 53, 624-630.

5. Lynd, L.R.; Laser, M.S.; Bransby, D.; Dale, B.E.; Davison, B.; Hamilton, R.; Himmel, M.E.; Keller, M.; McMillan, J D.; Sheehan, J.J.; Wyman, C.E. How biotech can transform biofuels. Nature Biotechnol. 2008, 26, 169-172.

6. Bartacek, J.; Zabranska, J.; Lens, P.N.L. Developments and constrains in fermentative hydrogen production. Biofuels, Bioprod. Biorefin. 2007, 1, 201-214.

7. Tilman, D.; Socolow, R.; Foley, J.A.; Hill, J.; Larson, E.; Lynd, L.; Pacala, S.; Reilly, J.; Searchinger, T.; Somerville, C.; Williams, R. Benefi cial Biofuels-The Food, Energy, and Environment Trilemma. Science 2009, 325, 270-271. 
8. Searchinger, T.; Heimlich, R.; Houghton, R.A.; Dong, F.; Elobeid, A.; Fabiosa, J.; Tokgoz, S.; Hayes, D.; Yu, T.-H. Use of U.S. croplands for biofuels increases greenhouse gases through emissions from land use change. Science 2008, 319, 1238-1240.

9. Herrera, S. Bonkers about biofuels. Nature Biotechnol. 2006, 24, 755-760.

10. Marris, E. Drink the best and drive the rest. Nature 2006, 444, 670-672.

11. Karp, A.; Shield, I. Bioenergy from plants and the sustainable yield challenge. New Phytologist 2008, 179, 15-32.

12. Bowyer, J.L.; Stockmann, V.E. Agricultural residues: An exciting bio-based raw material for the global panels industry. Forest Product J. 2001, 51, 10-21.

13. Kirilenko, A.P.; Sedjo, R.A. Climate change impacts on forestry. Proc. Nat. Acad. Sci. USA 2007, 104, 19697-19702.

14. Fenning, T.M.; Gershenzon, J. Where will the wood come from? Plantation forests and the role of biotechnology. Trends Biotechnol. 2002, 20, 291-296.

15. Righelato, R.; Spracklen, D.V. Carbon mitigation by biofuels or by saving and restoring forests? Science 2007, 317, 902.

16. Fenning, T.M.; Walter, C.; Gartland, K.M.A. Forest biotech and climate change. Nature Biotechnol. 2008, 26, 615-617.

17. Ornstein, L.; Aleinov, I.; Rind, D. Irrigated afforestation of the Sahara and Australian Outback to end global warming. Clim. Change 2009, 97, 409-437.

18. Climate Change 2007: The Physical Science Basis. IPCC: Geneva, Switzerland, 2007.

19. Invicta Capital Plans $£ 300 m$ Fund to Invest in Scottish Biomass Power Plants. Available online: http://www.localpower.org/nar_news.html?si=2737 (accessed on 28 January 2010).

20. Li, A.; Antizar-Ladislao, B.; Khraisheh, M. Bioconversion of municipal solid waste to glucose for bio-ethanol production. Bioprocess. Biosyst. Eng. 2007, 30, 189-196.

21. Demirbas, A. Biogas production from the organic fraction of municipal solid waste. Energy Sources Part A 2006, 28, 1127-1134.

22. Anselmo, P.; Badr, O. Biomass resources for energy in North-eastern Brazil. Appl. Energy 2004, 77, 51-67.

23. McIvor, A.; Evans, L. A sustainable biofuelled future? Cleantech 2008, 1, 5-9.

24. Gressel, J. Transgenics are imperative for biofuel crops. Plant Sci. 2008, 174, 246-263.

25. Fairless, D. Biofuel: the little shrub that could - maybe. Nature 2007, 449, 652-655.

26. Azam, M.M.; Waris, A.; Nahar, N.M. Prospects and potential of fatty acid methyl esters of some non-traditional seed oils for use as biodiesel in India. Biomass Bioenergy 2005, 29, 293-302.

27. McCoy, M. Boon for biofuels. C\&EN 2007, 9, 9.

28. Chisti, Y. Biodiesel from microalgae beats bioethanol. Trends Biotechnol. 2007, 26, 126-131.

29. Li, Y.; Horsman, M.; Wu, N.; Lan, C.Q.; Dubois-Calero, N. Biofuels from microalgae. Biotechnol. Progr. 2008, 24, 815-820.

30. Maritime policy: the state of the ocean. In Research*EU, European Commission: Brussels, Belgium, December 2007.

31. Fargione, J.; Hill, J.; Tilman, D.; Polasky, S.; Hawthorne, P. Land clearing and the biofuel carbon debt. Science 2008, 319, 1235-1238. 
32. Cançado, J.E.D.; Saldiva, P.H.N.; Pereira, L.A.A.; Lara, L.B.L.S.; Artaxo, P.; Martinelli, L.A.; Arbex, M.A.; Zanobetti, A.; Braga, A.L.F. The impact of sugar cane - burning emissions on the respiratory system of children and the elderly. Nature 2006, 114, 725-729.

33. Martinelli, L.A.; Filoso, S. Polluting effects of Brazil's sugar-ethanol industry. Nature 2007, 445, 364.

34. Marull, J.; Pino, J.; Tello, E. The loss of landscape efficiency: An ecological analysis of land-use changes in Western Mediterranean agriculture (Vallès county, Catalonia, 1853-2004). Global Environment. Global Environment 2008, 2, 112-150; available online: http://www.ub.edu/histeco/ pdf/marull-pino-tello.pdf

35. Marull, J.; Pino, J.; Tello, E.; Cordobilla, M.J. Social metabolism, landscape change and land-use planning in the Barcelona Metropolitan Region. Land Use Policy 2010, 27, 497-510.

36. Dornburg, V.; Lewandowski, I.; Patel, M. Comparing the land requirements, energy savings, and greenhouse gas emissions reduction of biobased polymers and bioenergy. J. Ind. Ecol. 2009, 7, 93-116.

37. Our Common Future. United Nations: Nairobi, Kenya, 1987,

38. Bennet, S. The biorefinery concept. Cleantech 2008, 1, 14-15.

39. Maas, R.H.; Bakker, R.R.; Boersma, A.R.; Bisschops, I.; Pels, J.R.; de Jong, E.; Weusthuis, R.A.; Reith, H. Pilot-scale conversion of lime-treated wheat straw into bioethanol: quality assessment of bioethanol and valorization of side streams by anaerobic digestion and combustion. Biotechnol. Biofuels 2008, 1, 14.

40. White, J.S.; Yohannan, B.K.; Walker, G.M. Bioconversion of brewer's spent grains to bioethanol. FEMS Yeast Res. 2008, 8, 1174-1184.

41. Larsen, J.; Østergaard Petersen, M.; Thirup, L.; Li, H.W.; Iversen, F.K. The IBUS process lignocellulosic bioethanol close to a commercial reality. Chem. Eng. Technol. 2008, 31, 765-772.

42. The Scottish Government. Available online: http://www.scotland.gov.uk/Home (accessed on 25 January 2010).

43. Projects in Biomass Process and Sustainability Analyses. Available online: http://www.nrel.gov/ biomass/proj_process_sustainability.html (accessed on 25 January 2010).

44. Geoengineering the climate: Science, governance and uncertainty. The Royal Society: London, UK, 2009; Available online: http://royalsociety.org/geoengineeringclimate/ (accessed on 28 January 2010).

(C) 2010 by the authors; licensee Molecular Diversity Preservation International, Basel, Switzerland. This article is an open-access article distributed under the terms and conditions of the Creative Commons Attribution license (http://creativecommons.org/licenses/by/3.0/). 